\title{
Surgical Management of Dystocia due to Monocephalus Thoracopagus Tetrabrachius Tetrapus Dicaudatus Monster Foetus by Caesarean Section- A Case Report
}

\author{
B. M. Nijin Jos* \\ Veterinary Surgeon, Veterinary Dispensary, Cumbummettu \\ Kerala Animal Husbandry Department, India \\ *Corresponding author
}

\section{A B S T R A C T}

\section{Keywords}

Calf, Dystocia,

Fetal monster,

Thoracopagus,

Tetrabrachius,

Tetrapus, Caesarean section

\section{Article Info}

Accepted:

22 June 2020

Available Online:

10 July 2020
A conjoined monster calf was delivered by caesarean section in a crossbred Holstein Friesian heifer. The calf was partially duplicated with single head (Monocephalic), two male foetuses joined at the thoracic region (Thoracopagus) and having well developed eight limbs that is four fore limbs (Tetrabrachius) and four hind limbs (Tetrapus) and both pelvis were separate (Dicaudatus). The occurrence of foetal monstrosities often leads to difficulty in parturition and also failed to be delivered by mutational operations. The present report records a successful management of dystocia due to monocephalic thoracopagus tetrabrachius tetrapus monster calf in a crossbred Holstein Friesian by caesarean section.

\section{Introduction}

Dystocia or difficulty in parturition can be due to maternal or fetal origin. Bovine practitioners are often presented with such condition where scientific manipulation is required to correct the presentation to bring about a normal delivery. Caesarean section is considered when the fetus cannot be delivered by fetal mutation and extraction (Schultz et al., 2008). Absolute fetal oversize, malposition, fetal anasarca, schistosoma reflexus, hydrocephalus, conjoined twins, emphysematous, mummification, and prolonged gestation (Campbell and Fubini, 1990) etc. are the conditions that are of fetal origin that can lead cesarean section.

Monsters are abnormal fetuses that usually have altered appearance (Purohit, 2006), results from developmental disturbances that involves various organs and systems (Vegad, 2007). They are usually associated with either with infectious diseases or congenital defects (Arthur et al., 2001) and may or may not interfere with birth (Sharma et al., 2010; 
Gupta et al., 2011). Abnormal duplication of germinal area in fetus will give rise to congenital fetal abnormalities with partial duplication of body structure (Roberts, 2004). Dystocia is a common sequel of monstrosity, so it is important to know various types of monsters which cannot be removed without Caesarean section or fetotomy most of the time (Gupta et al., 2011).

This communication reports a rare case of conjoined monster calf (Monocephalus Thoracopagus Tetrabrachius Tetrapus Dicaudatus) in a cross bred Holstein Friesian heifer which was relieved by caesarean section.

\section{Case history and clinical observations}

A three year old crossbred Holstein Friesian heifer was presented to veterinary dispensary cumbummettu in sternal recumbency with history of full term gestation and shows severe straining since last 8 hours, water bag ruptured few hours before but the animal is not able to deliver the calf. Detailed Gynaecoclinical examination revealed that the birth canal was completely impacted with four limbs and head. Per vaginal examination revealed no demarcation of thorax and four limbs could be palpated at untoward places. The condition was tentatively diagnosed as fetal monster.

\section{Treatment}

The surgical procedure was done under Xylazine hydrochloride sedation at the rate of $0.1 \mathrm{mg}$ per Kilogram bodyweight intramuscularly and regional anaesthesia was accomplished by inverted L block using 2\% Lignocaine. The animal was placed in right lateral recumbency and the surgical site was clipped shaved and prepared for aseptic surgery. An oblique incision was made in the left lower flank downward and forward. The incision was deepened by incising through the muscle layers and peritoneum to reach the abdominal cavity. The uterus was exteriorized and a knick incision was made in the uterus which was extended with scissors. The foetus was tracted out gently after careful manipulation. The uterine incision was closed with catgut (Size 1) in double layer inversion suture pattern, thereafter muscles and skin was apposed in routine manner. Polyglycolic acid 1 suture was used for apposing muscle layers and Nylon for skin. Post operatively the dam was maintained on fluids, antibiotics and other supportive therapy. The animal was reported to have recovered uneventfully.

\section{Results and Discussion}

A cross bred Holstein Friesian heifer presented with dystocia was diagnosed with foetal monster on per vaginal examination. Caesarean section was performed to remove the foetus from the dam. The calf when removed after caesarean section was found to be monocephalus tetrabrachius tetrapus dicaudatus monster. The dam was administered fluids, antibiotics and other supportive therapy post operatively. The animal reported to have recovered uneventfully.

Fetal monstrosity develops when a disturbance occurs in the development of various organs and systems which can cause a great distortion in the individual (Vegad, 2007). The incidence of fetal monstrosities is rare but when it occurs it often leads to caesarean section or fetotomy (Sharma et al., 2013). Dystocia that occur due to fetal monsters are relieved by caesarean section more than fetotomy as it is of limited usefulness except in a few cases of monsters (Dholpuria et al., 2016). Caesarean section can be done in the left oblique ventro-lateral site, as this site causes minimum post operative contaminations and lesser postoperative complications (Verma et al., 1974 and Singh et al., 1978). 
Fig.1 Monocephalus thoracophagus tetrabrachius teterapus dicaudatus monster calf delivered through caesarean section

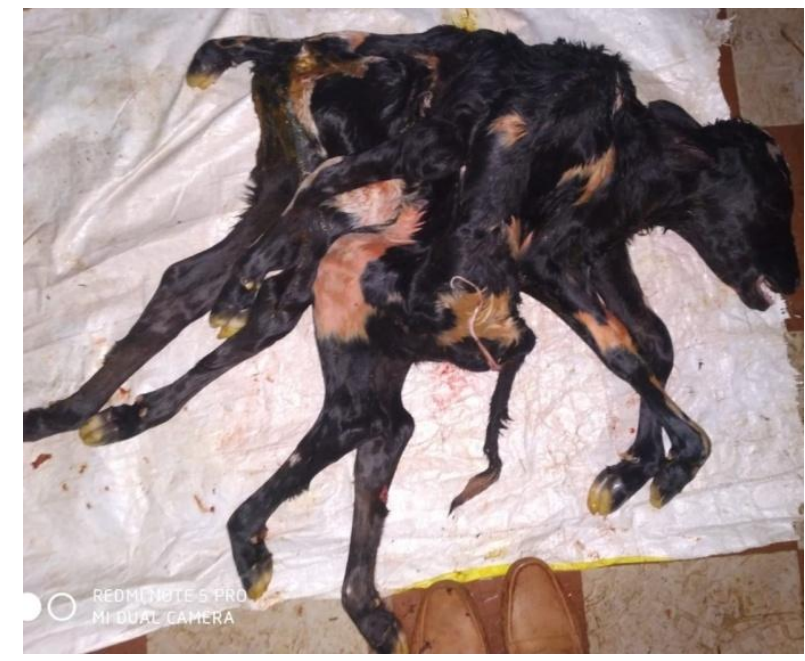

\section{Acknowledgement}

The author would like to acknowledge Director, Kerala Animal husbandry Department and District Animal Husbandry Office, Idukki for providing the facilities for the successful completion of the work.

\section{References}

Arthur, G. H., Noakes, D. E., Pearson, H., Parkinson, T. J. 2001. Veterinary Reproduction and Obstetrics. Edn 8, Vol. I, W.B. Saunders Co. Ltd. London, England. 544-545.

Campbell, M.E. and Fubini, S.L. 1990. Indications and surgical approaches for cesarean section in cattle. Compend Contin. Educ. Pract. Vet. 12: 285-292.

Dholpuria, S., Saraswat, C. S., Thanvi, P. and Sharma, S. 2016. Per-vaginal successful management of a rare case of dystocia in murrah buffalo due to dicephalus thoracophagus tetrabrachius tetrapus and dicaudatus monster: A case report. Theriogenology. 6(1): 35-40.

Gupta, V. K., Sharma, P., Shukla, S. N. 2011. Dicephalus monster in a Murrah buffalo. Indian Vet. J. 88(12): 72-73.

Purohit, G. N. 2006. Dystocia in sheep and goat - A review. J. Small Ruminants. 12(1):1-12.

Roberts, S.J. 2004. Veterinary Obstetrics and Genital Diseases. CBS Publishers, New Delhi. India.

Schultz, L.G., Tyler, J.W., Moll, H. D., and Constantinescu, G.M. 2008. Surgical approaches for cesarean section in cattle. Can. Vet. J. 49(6): 565-568.

Sharma, A., Kumar, P., Singh, M., Vasishta, N. K., and Jaswal, R. 2013. Rare fetal monster in Holstein crossbred cow. Open Vet. J. 3(1): 8-10.

Sharma A, Sharma S, Vasishta VK. A diprosopus buffalo neonate: A case report. 2010. Buffalo Bulletin. 29(1):6264.

Singh, J.; Prasad, B. and Rathor, S.S. 1978. Torsio uteri in buffaloes (Bubalus bubalis)- An analysis of 65 cases. Indian Vet. J. 55:161-165.

Vegad, J.L. 2007. 2nd edition. International book distribution Company; 2007. Textbook of Veterinary general pathology.

Verma, S.K.; Manohar, M. and Tyagi, R.P.S. 1974. Cesarean section in bovines: A clinical study. Indian Vet. J. 51:471479. 


\section{How to cite this article:}

Nijin Jos, B. M. 2020. Techniques for Determination of Vitamin B6, Vitamin C and Variability in Areca Nut (Areca catechu) Samples of Karnataka, India. Int.J.Curr.Microbiol.App.Sci. 9(07): 2873-2876. doi: https://doi.org/10.20546/ijcmas.2020.907.340 